\title{
Financial Inclusion and Household Wellbeing in Namibia
}

\author{
Alfred Kechia Mukong \\ https://orcid.org/0000-0003-1632-3341 \\ University of Namibia \\ amukong@unam.na
}

\author{
Elina M. Amadhila \\ https://orcid.org/0000-0003-0329-4406 \\ University of Namibia \\ eamadhila@unam.na
}

\begin{abstract}
Purpose: Financial inclusion is increasingly being recognised as having an important influence on household wellbeing, as it provides resources and income, enhances consumption and investment in productive assets and stimulates overall economic growth. In this paper, we examine the impact of financial inclusion on household wellbeing in Namibia.

Design/methodology: Using data extracted from the 2017 Namibia Financial Inclusion Survey, a UNDP approach for computing human development indices is used to generate a wellbeing index. Two-stage least squares regression analysis is employed to address the potential endogeneity associated with financial inclusion.

Findings: The results suggest the positive and significant effects of financial inclusion on household wellbeing. The effects are consistent across location and gender when different methodological approaches are applied. Household characteristics such as education, income, and financial decisions, are important determinants of household wellbeing.

Implications: National and international agencies are encouraged to promote policies that enhance the ability of both the public and private sector to innovate and expand financial services to vulnerable populations.

Originality/value: An inclusive financial system is key in determining the level of household wellbeing, but many studies have utilised macro time-series data as opposed to household data, to tease out this relationship.
\end{abstract}

Keywords: financial inclusion; wellbeing; Namibia

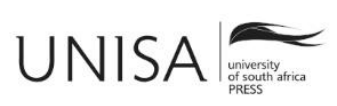




\section{Introduction}

Financial inclusion, a process of ensuring easy access, availability and usage of formal financial services for all members of an economy, promotes inclusive growth, a better livelihood and poverty reduction (Allen et al. 2013a; Kumar and Mishra 2011; Park and Mercado 2018). An inclusive financial system facilitates the allocation of productive resources, improves day-to-day management of finances, and reduces the growth of costly and often exploitative informal credit sources. Thus, an all-inclusive financial system provides avenues for secure and safe saving practices and facilitates a whole range of efficient financial services, thereby enhancing efficiency and welfare (Park and Mercado 2018; Sarma and Pais 2011; Tita and Aziakpono 2017). As a consequence, in recent decades, pro-poor growth policies have recognised an inclusive financial system as one of the most important instruments for achieving inclusive growth; therefore, financial inclusion has become a policy priority for many countries (Haq, Ismail, and Satar 2018; Sarma and Pais 2011). However, global statistics suggest that $69 \%$ of eligible adults have an account with a formal financial institution, a rise from $62 \%$ in 2014 (Demirgüç-Kunt et al. 2018). Developing countries experienced a greater rise from $54 \%$ to $63 \%$, but the distribution of formal financial services is skewed to urban areas, leaving a significant proportion of the vulnerable population in both rural and semiurban areas unbanked (Allen et al. 2013b).

While sub-Saharan African countries have made steady progress in the financial inclusion index, the progress differs significantly across countries. The region continues to have the highest number of individuals and households without access to basic formal financial services, and it was estimated that Africa risks being home to $70 \%$ of the world's poor by the end of 2019 (Coulibaly 2019). Concerning wellbeing, financial inclusion has been widely acknowledged as having the potential to reduce poverty (Chibba 2009; Imai, Arun, and Annim 2010; Koomson, Vilano, and Hadley 2020; Mohammed, Mensah, and Gyeke-Dako 2017; Park and Mercado 2018; Swamy 2014). Despite vast evidence on the relationship between financial inclusion and poverty, existing studies at household level are limited and highly aggregated with less focus on gender and geographic location (Koomson et al. 2020). With recent evidence from the 2017 Global Financial Index Database pointing to significant gender and location gaps in financial inclusion, it is imperative to extend the discourse to cover gender and location differentials in financial inclusion and wellbeing. Based on this, Koomson et al. (2020) show that financial inclusion prevents households' exposure to poverty with a greater effect on female-headed households and rural communities in Ghana. This paper builds on the study by Koomson et al. (2020) in order to estimate the relationship between financial inclusion and wellbeing in Namibia, a country with one of the highest levels of financial inclusion and inequality.

A considerable body of research has explained the reasons for unequal access to formal financial services between individuals and households and across countries (Akudugu 2013; Kumar 2013; Sarma and Pais 2011; Zins and Weill 2016). Another body of 
evidence suggests that financial inclusion significantly promotes access to basic livelihood facilities, reduces poverty and lowers income inequality (Tita and Aziakpono 2017; Koomson et al. 2020; Masiyandima, Mlambo, and Nyarota 2017; Park and Mercado 2018; Sarma and Pais 2011). The majority of these studies provide macrobased evidence using time series or panel data for a heterogeneous group of countries (Park and Mercado 2018; Sarma and Pais 2011) as opposed to individual and household data. Thus, there is little evidence in the context of individual or household wellbeing (Koomson et al. 2020). Evidence based on individual and household data is further limited in that existing studies consider very few indicators of wellbeing (Masiyandima et al. 2017) and others have treated wellbeing as a binary outcome (Koomson et al. 2020). This suggests that country-specific studies using individual or household data and more comprehensive indicators of wellbeing, may be required for better policy options. Policymakers and donors desire that access to financial services (including credit, savings, insurance and money transfers), provided by a variety of financial service providers, will allow poor and low-income households in low and middleincome countries to enhance their welfare, grasp opportunities, mitigate shocks and ultimately escape poverty. They also hope that financial inclusion will advance macroeconomic development (Beck, Demirgüç-Kunt, and Levine 2007; Duvendack and Mader 2020).

In the research that directed this paper, we empirically analysed the relationship between financial inclusion and household wellbeing in Namibia, by utilising household level data as opposed to using macro time-series data. We therefore hypothesised a positive relationship between financial inclusion and wellbeing. Building on existing findings, we extended the analysis by using data from a national representative survey; this allowed for the use of broader and more comprehensive indicators of household wellbeing. We further disaggregated the analysis to account for the role of gender and location differentials. Country-specific case studies are essential, since the extent to which the effect of financial inclusion for one country can be generalised to other countries, has not been established. In addition, the magnitude of the relationship is expected to vary significantly by gender and location, and may also vary, depending on which indicators of wellbeing are considered. The paper, therefore, contributes to the existing literature in three ways: firstly, this is one of the first studies to quantify the effects of financial inclusion on household wellbeing in Namibia; secondly, we adopted the United Nations Development Programme (UNDP) approach with more comprehensive indicators to construct a wellbeing index; thirdly, we implemented estimation strategy controls for preference heterogeneity by estimating the separate effect of financial inclusion on the wellbeing of households by their location and the gender of the head of household.

Relative to many African countries, Namibia has one of the highest levels of financial inclusion. According to the 2017 Namibia Financial Inclusion Survey (NFIS) ${ }^{1}$, about

1 Namibia Statistics Agency (2017). "Namibia Financial Inclusion Survey.” NSA, Windhoek, Namibia. 
$78 \%$ of eligible adults are financially included, relatively above the current global average of 69 per cent (Demirgüç-Kunt et al. 2018). More interestingly, women are more financially included than men, though people in rural areas are less financially included. The reasons cited for the lower inclusion of people in rural areas are customised products, too many documents, and the requirement of collateral (Khan and Bhandari 2018). Ironically, Namibia remains one of the most unequal countries in the world, with a very slow pace of poverty reduction (World Bank Group 2021); yet financial exclusion is often blamed for inequalities (Duvendack and Mader 2020). This is worrisome, given the suggested positive relationship between financial inclusion and poverty reduction. Motivated by this observation, we assessed the extent to which financial inclusion has influenced access to basic wellbeing indicators in Namibia.

\section{Methodology}

\section{Data}

The analysis was based on the 2017 Namibia Financial Inclusion Survey (NFIS), the fourth financial inclusion survey for Namibia; however, the first to be collected by the Namibia Statistics Agency (NSA). The survey targeted 2114 households from all 14 regions of Namibia. The survey interviewed individuals drawn from a geographically representative sample of 1863 households. A stratified three-stage cluster sampling design was used to select eligible individuals. The first stage selected a sample of 151 enumeration areas (EAs) based on the EAs of the 2011 population census. Households were randomly selected from the 151 EAs and eligible members aged 16 years or older were interviewed.

The survey has rich individual and household level information and demographics on aspects that relate to financial inclusion, its determinants, landscape, access, and access constraints. The information contained in the survey includes access to financial products and services, the drivers and barriers to the usage of financial services, and individual opinion rating access challenges for basic indicators of the standard of living - including access to food, health, education, and material wellbeing. The indicators of financial inclusion and household wellbeing are the important variables and we discuss in detail how these variables were measured in the study.

Financial inclusion is measured in terms of having access to and use of formal financial products and services. The indicators of financial inclusion commonly used in the literature, include, ownership of an active account with a bank or any formal financial institution, access to credit and saving services from a formal financial institution (Akudugu 2013; Honohan 2008; Masiyandima et al. 2017; Zins and Weill 2016). In our data collection, people were asked whether or not they had a formal bank account, a formal savings account or if they could access credit from financial institutions. These indicators allowed us to assess the differential effect of overall banking inclusion on household wellbeing. Overall banking inclusion denotes access to a deposit or a loan account from a formal banking institution. In the empirical analysis, we first considered 
the independent effect of each of these indicators of financial inclusion on wellbeing. In the second stage, we considered the joint effects with the objective of distinguishing between the different levels of inclusivity of households. It was expected that more financially included households (having access to all three indicators of inclusion) should experience higher levels of wellbeing than their counterparts.

\section{Theoretical Framework on Financial Inclusion and Wellbeing}

Within the financial development framework, there are direct and indirect linkages between financial inclusion and wellbeing or poverty. Financial inclusion broadens access to credit, insurance and other financial services, provides resources and income for individual or household needs, and enhances investment, entrepreneurial possibilities and overall economic growth, thereby improving consumption and wellbeing (Demirgüç-Kunt et al. 2018; Rajan and Zingales 1998). Access to financial services enables the disadvantaged population to invest in productive assets such as new technologies, education and health (Jalilian and Kirkpatrick 2002), enhancing their potential to achieve a better livelihood (World Bank 2001). For indirect linkages, it is argued that financial inclusion induces economic growth, which then gradually benefits the poor through job creation and increased government spending on education, health and social protection (Abosedra, Shanbaz, and Nawaz 2016). Theoretical evidence that underpins the relationship between financial inclusion and wellbeing is detailed in Koomson et al. (2020) and our paper adopts the conceptual framework proposed by this study (figure 1). In the conceptual framework, financial inclusion is measured as access and use of financial services, whereas wellbeing is measured in terms of poverty and vulnerability to poverty. However, we measured household wellbeing in terms of assets ownership and the UNDP (2014) approach for computing human development indices (HDIs) to generate an index for wellbeing.

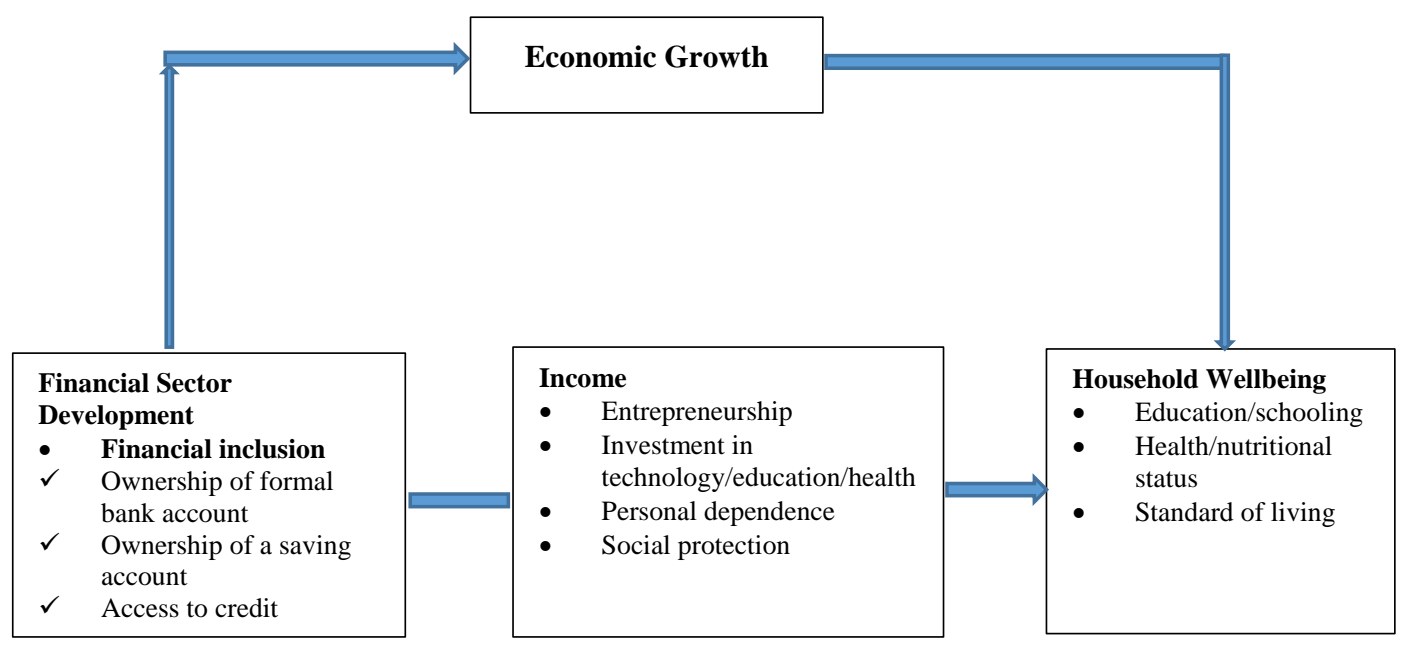


Figure 1: Conceptual link between financial inclusion and wellbeing (Koomson et al. 2020)

\section{Measurement of Wellbeing}

Wellbeing is a multi-dimensional concept embracing elements such as income and consumption, living standards, self-reported happiness (life satisfaction), quality of life, and empowerment. Based on these dimensions, wellbeing can be viewed as an objective (economic and social aspects) and subjective (psychological aspects) concept (Dolan, Peasgood, and White 2008; Kahneman and Krueger 2006; Yang 2018). In this paper, we focused on the objective measure of wellbeing. Three dimensions, namely living standards, health, and education, are often chosen as objective outcomes for evaluating wellbeing across the international community. ${ }^{2}$ Although this approach has been generally criticised in welfare economics literature, it still remains one of the most influential and widely used measures of wellbeing in the research and policy arena (Yang 2018).

We adopted the UNDP (2014) approach for computing human development indices (HDIs). This approach standardises indicators that are measured on different scales into indices. In table 1 , we present the different dimensions and indicators used in computing the index for household wellbeing. We create indices for each dimension and aggregate them into a composite index, since the selected indicators for these dimensions are measured according to different scales. The HDIs are computed as follows:

$$
x_{i k}=\frac{\left(\widetilde{x_{i k}}-x_{k}^{\text {min }}\right)}{\left(x_{k}^{\text {max }}-x_{k}^{\text {min }}\right)}
$$

Where $\widetilde{x_{i k}}$ is the actual value in indicator $k$ for household $i, x^{\min }{ }_{k}$ and $x^{\max }{ }_{k}$ are respectively, the minimum and maximum values of the indicator $k$ in the whole data set (e.g., 1 and 4 respectively for education, table 1). The generated indices are standardised and free of measurement unit and are expected to range from 0 to 1, indicating a low to high score respectively. After standardisation, the values of the dimensions with more than one indicator are derived by averaging the values of the different indicators as follows:

$$
C_{i}=\frac{\sum_{i=1}^{n} \operatorname{Index} A_{i}}{n}
$$

Where $C_{i}$ is one of the dimensions for household $i$, Index $A_{i}$ is the indicator(s) that make(s) up a given dimension and $n$ the number of indicators in each dimension. After

2 UNDP (2014). “Human Development Report 2014” (Technical Note). United Nations Development Program, New York. 
obtaining the values of all dimensions, the composite wellbeing score is computed by averaging all the dimensions as follows:

$W_{i}=\frac{\sum_{i=1}^{n=1} C_{i}}{N}$

Where $W_{i}$ represents the composite score measuring the wellbeing of household $i$ and $N$ is the total number of dimensions contributing to the wellbeing index (three dimensions in our case). The composite score ranges from 0 to 1 , with high values indicating a high level of wellbeing.

Table 1: Variables used in computing the composite wellbeing index

\begin{tabular}{|l|l|l|l|}
\hline $\begin{array}{l}\text { Dimensions of } \\
\text { wellbeing }\end{array}$ & Indicators & Not deprived for maximum weight & Weight \\
\hline Education & Child schooling & Unable to send children to school & $1 / 4$ \\
\hline Health/healthcare & Nutrition & Can't afford food for household & $1 / 4$ \\
\hline & Healthcare & No access to medical care & $1 / 4$ \\
\hline & $\begin{array}{l}\text { Access to safe } \\
\text { drinking water }\end{array}$ & $\begin{array}{l}\text { Household sources of drinking water } \\
\text { are protected }\end{array}$ & $1 / 6$ \\
\hline & $\begin{array}{l}\text { Access to } \\
\text { improved } \\
\text { sanitation }\end{array}$ & $\begin{array}{l}\text { Household sanitation facility } \\
\text { improved }\end{array}$ & $1 / 6$ \\
\hline Standard of living & $\begin{array}{l}\text { Type of cooking } \\
\text { fuel }\end{array}$ & $\begin{array}{l}\text { The household cooks with coal, } \\
\text { wood, gas or electricity. } \\
\text { Access to more than one radio, TV, } \\
\text { telephone, bike }\end{array}$ & $1 / 6$ \\
\hline & Asset ownership & $\begin{array}{l}\text { Access to motorbike, refrigerator, } \\
\text { microwave } \\
\text { Access to a washing machine, } \\
\text { furniture and a car or truck }\end{array}$ & $1 / 2$ for \\
each
\end{tabular}

Notes: For education and health, the value of 1 indicates that the household always has challenges regarding education, food and health services and 4 indicates that the household has never had any of these challenges. The value of 1 for sanitation, safe drinking water and cooking fuel indicates access to the poorest facility and 6 indicates access to the cleanest facility. For asset ownership, the value of 1 indicates no access and 2 indicates access to each of the listed items.

\section{Estimation Strategy}

The analysis focuses on the relationship between financial inclusion and household wellbeing. The econometric model is specified as follows: 
$W_{i}=\beta_{0}+\beta_{1} F I_{i}+\beta_{2} X_{i}+\varepsilon_{i}$

Where $W_{i}$ is the composite score measuring the wellbeing of households $i, F I_{i}$ is the household financial inclusion status, $X_{i}$ is a vector of household characteristics presented in table $2, \beta_{i}$ a vector of parameters to be estimated, and $\varepsilon_{i}$ is a random error term. Given that our dependent variable is continuous, equation 4 can be estimated using an ordinary least square (OLS) regression technique. However, the financial inclusion variable is considered to be endogenous because of the unobserved transaction cost in the link between FI and wellbeing and thus, the use of an OLS yield biased estimate (Koomson and Ibrahim 2018; Koomson et al. 2020; Swamy 2014). Distance to the nearest financial institution (measured in hours) is used as an instrumental variable to address the endogeneity problem, as it satisfies the conditions of a valid instrument as follows: First, distance to the nearest financial institution has a direct relationship with the endogenous variable (financial inclusion) but not with wellbeing (Koomson et al. 2020). That is, the longer the distance to the nearest bank, the higher the financial in-kind and psychic costs and the lower the level of access to financial services (Brown, Guin, and Kirschenmann 2015). The first stage regression results confirm this relationship (tables 4 and 5); Second, distance to the nearest financial institution only influences wellbeing through its influence on the financial inclusion indicators. Thus, equation 4 is estimated using both the standard OLS and the 2SLS regression techniques.

\section{Results and Discussion}

\section{Descriptive Statistics}

In figure 2, we present a preliminary look at the spatial distribution of the rate of financial inclusion and level of household wellbeing by the different regions of Namibia. To do this, we use the shapefiles for Namibia and the computed regional averages as a proportion of the national averages gleaned from the financial inclusion survey. From the key, a value of one, less than one and/or greater than one denotes regions with the rate of financial inclusion or level of wellbeing equal to, smaller than, and/or larger than the national rate and level respectively. Specifically, the darker in colour a region is on the map, the higher the rate of financial inclusion and wellbeing relative to the national rate. The figure immediately indicates that only half (7) of the 14 regions in Namibia drive the observed high level of financial inclusion (region's financial inclusion rate is at least as good as the national rate) in Namibia. Similarly, there is a high level of inequality in household wellbeing between regions, with about six regions having levels of wellbeing that are at least as good as the national level. 


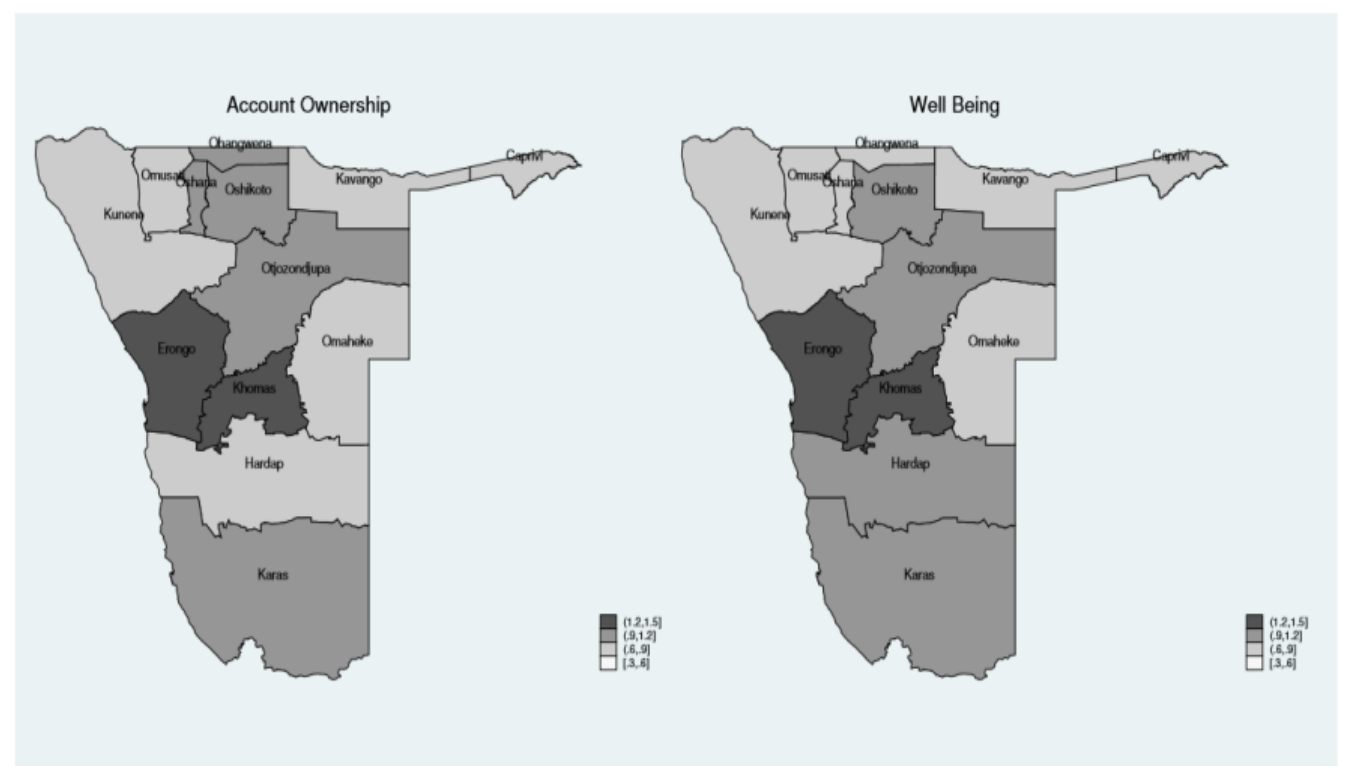

Figure 2: Regional rate of financial inclusion and level of wellbeing as a proportion of the national rate

Notes: Colouring of the map goes from dark, denoting a high rate of account ownership at a formal institution or high level of wellbeing, to light, denoting a low rate of account ownership or low level of wellbeing, relative to the national average.

As expected, regions with a high rate of financial inclusion are also experiencing relatively high levels of wellbeing. Intuitively, this indicates a positive association between financial inclusion and household wellbeing. The map depicts that the Erongo and Khomas regions have the highest proportion of financially included households as well as the highest levels of wellbeing. Their averages are far higher than the national averages. On the other hand, the Omaheke, Kavango, Caprivi (Zambezi) and Omusati regions have the lowest rates. This figure presents a picture of the level of wellbeing across regions and is consistent with evidence of the distribution of regional inequality and wellbeing in the country. ${ }^{3}$

Table 2 reports summary statistics of wellbeing by household characteristics, revealing the interesting differences between financially excluded and included households. The results demonstrate that about $75 \%$ of the sample have accounts with a formal financial institution, $62 \%$ have access to saving services, and only $16 \%$ have access to formal credit. Only $15 \%$ of the sample have access to all three indicators of financial inclusion, $48 \%$ have access to two indicators, and $11 \%$ have access to only one indicator. In terms of household wellbeing, the average household wellbeing score for Namibia is 0.61 . On

3 National Planning Commission (2016). "Namibia Poverty Mapping." Windhoek, Namibia. 
average, there are four persons in a household and the average age of the household head in the sample is 39 years.

Table 2: Descriptive statistics for difference in wellbeing by household characteristics

\begin{tabular}{|l|l|l|l|l|l|}
\hline & $\mathbf{( 1 )}$ & $\mathbf{( 2 )}$ & $\mathbf{( 3 )}$ & $\mathbf{( 4 )}$ & $\mathbf{( 5 )}$ \\
\hline Variable & Mean & Std Dev. & Mean & Std Dev. & Diff \\
\hline Household wellbeing score & 0.609 & $(0.195)$ & & & \\
\hline Household size & 4.147 & $(3.014)$ & & & \\
\hline Age of household head & 38.757 & $(16.339)$ & & & \\
\hline Household per capita income & 3,202 & $(41,133)$ & & & \\
\hline Have account with formal institution & 0.748 & $(0.434)$ & 0.653 & $(0.188)$ & $0.172^{* *}$ \\
\hline Have access to saving services & 0.624 & $(0.485)$ & 0.666 & $(0.186)$ & $0.152^{* *}$ \\
\hline Have access to credit & 0.163 & $(0.369)$ & 0.778 & $(0.159)$ & $0.201^{* *}$ \\
\hline Reside in an urban area & 0.470 & $(0.499)$ & 0.700 & $(0.195)$ & $0.170^{* *}$ \\
\hline Household head is male & 0.564 & $(0.496)$ & 0.620 & $(0.191)$ & $0.189^{* *}$ \\
\hline Household head is married & 0.536 & $(0.471)$ & 0.593 & $(0.205)$ & $-0.24^{* *}$ \\
\hline Cooperate in financial decisions & 0.425 & $(0.494)$ & 0.619 & $(0.201)$ & $0.017^{*}$ \\
\hline No formal education & 0.110 & $(0.313)$ & 0.472 & $(0.151)$ & $-0.154^{* *}$ \\
\hline Primary education & 0.253 & $(0.435)$ & 0.496 & $(0.154)$ & $-0.152^{* *}$ \\
\hline Secondary education & 0.540 & $(0.499)$ & 0.649 & $(0.176)$ & $0.087^{* *}$ \\
\hline Tertiary education & 0.096 & $(0.295)$ & 0.840 & $(0.129)$ & $0.256^{* *}$ \\
\hline No access to any financial product & 0.252 & $(0.434)$ & 0.481 & $(0.157)$ & $-0.172^{* *}$ \\
\hline Access to one financial product & 0.113 & $(0.316)$ & 0.575 & $(0.178)$ & $-0.38^{* *}$ \\
\hline Access to two financial products & 0.484 & $(0.500)$ & 0.628 & $(0.179)$ & $0.038^{* *}$ \\
\hline Access to all three products & 0.151 & $(0.359)$ & 0.786 & $(0.155)$ & $0.208^{* *}$ \\
\hline
\end{tabular}

Notes: Standard deviation in parentheses. Columns (1)-(2) present statistics for the entire sample; columns (3)-(4) present statistics for wellbeing by household characteristics and column (5) presents differences in average wellbeing by household characteristics. *Denotes statistical significance at $10 \%, * *$ denotes significant at least at $5 \%$.

The results demonstrate that over $54 \%$ of the household heads are married and about $56 \%$ of the households are headed by men. The majority of the sample resides in rural areas $(53 \%)$ and only $43 \%$ of the households cooperate when it comes to making decisions about their finances. With regards to educational attainment of the household head, $11 \%$ have no formal education, $25 \%$ have completed primary education, $54 \%$ have completed secondary education, and only $10 \%$ have some tertiary education. 
Results in column 5 indicate that households residing in urban areas, as well as those that have access to financial services, cooperate in financial decisions and are headed by a male with a high level of education, and are more likely to have higher values on the wellbeing score than their respective counterparts.

Column 5 of table 2 presents differences in the mean of the wellbeing score by household specific characteristics. The average level of wellbeing is significantly higher among financially included households than their financially excluded counterparts. The wellbeing score is 0.17 units, significantly higher if they own an account with a formal financial institution, 0.15 units higher if they have access to saving services, and 0.20 units higher if they have access to formal credit. Households residing in urban areas are significantly more likely to have access to the wellbeing indicators, as shown in table 1. On average, the household wellbeing score of urban residents is 0.17 units higher than the score of rural residents. The average score for male-headed households is 0.19 units, significantly higher than the average score for female-headed households. The wellbeing score is 0.02 units, significantly higher for households that cooperate in making decisions about their finances. Households headed by individuals with some tertiary education and households with access to all three indicators of financial inclusion, have the highest level of wellbeing.

\section{Empirical results}

\section{Financial Inclusion and Household Wellbeing}

In this section, we consider the relationship between financial inclusion and household overall wellbeing. The analysis is motivated by the view that financial inclusion is not an end in itself, but rather a means of improving wellbeing and reducing poverty. The second motivation is that there is limited evidence of the relationship between financial inclusion and household wellbeing, and studies that have examined this relationship used a limited number of the indicators of wellbeing (Masiyandima et al. 2017). Finally, there are lessons to be learned from a country that has very high levels of financial inclusivity, yet experiences high levels of inequality. The regression estimates predicting the relationship between financial inclusion and household wellbeing are presented in table 3 . 
Table 3: Regression estimates of financial inclusion and household wellbeing

\begin{tabular}{|c|c|c|c|c|c|c|}
\hline \multicolumn{2}{|l|}{ Variables } & (2) & (3) & (4) & (5) & (6) \\
\hline \multicolumn{7}{|c|}{ Panel A: Individual measures of financial inclusion } \\
\hline \multirow[t]{2}{*}{ Have a formal bank account } & $0.045 * * *$ & $0.040 * * *$ & $0.071 * * *$ & $0.089 * * *$ & $0.060 * * *$ & $0.111 * * *$ \\
\hline & $(0.012)$ & $(0.014)$ & $(0.021)$ & $(0.014)$ & $(0.015)$ & $(0.023)$ \\
\hline \multirow{2}{*}{$\begin{array}{l}\text { Have a formal savings } \\
\text { account }\end{array}$} & $0.020^{*}$ & 0.022 & 0.018 & $0.060 * * *$ & $0.038 * * *$ & $0.063 * * *$ \\
\hline & $(0.011)$ & $(0.014)$ & $(0.017)$ & $(0.012)$ & $(0.014)$ & $(0.019)$ \\
\hline \multirow[t]{2}{*}{ Have access to credit } & $0.053 * * *$ & $0.056^{* * *}$ & $0.046^{* * *}$ & $0.152 * * *$ & $0.105 * * *$ & $0.123 * * *$ \\
\hline & $(0.010)$ & $(0.017)$ & $(0.013)$ & $(0.011)$ & $(0.017)$ & $(0.014)$ \\
\hline \multirow[t]{2}{*}{ Constant } & $0.245^{* * *}$ & $0.317 * * *$ & $0.219 * * *$ & $0.481 * * *$ & $0.461 * * *$ & $0.529 * * *$ \\
\hline & $(0.041)$ & $(0.051)$ & $(0.068)$ & $(0.008)$ & $(0.008)$ & $(0.015)$ \\
\hline $\begin{array}{l}\text { Household controls } \\
\text { included }\end{array}$ & Yes & Yes & Yes & No & No & No \\
\hline Observations & 1,800 & 960 & 840 & 1,861 & 986 & 875 \\
\hline R-squared & 0.481 & 0.288 & 0.433 & 0.241 & 0.138 & 0.229 \\
\hline \multicolumn{7}{|c|}{$\begin{array}{l}\text { Panel B: Measures of financial inclusion } \\
\text { combined }\end{array}$} \\
\hline Variables & (1) & (2) & (3) & (4) & (5) & (6) \\
\hline \multirow{2}{*}{$\begin{array}{l}\text { Financial inclusion (only } 1 \\
\text { indicator) }\end{array}$} & $0.047 * * *$ & $0.040 * * *$ & $0.073 * * *$ & $0.095^{* * *}$ & $0.061 * * *$ & $0.118 * * *$ \\
\hline & $(0.012)$ & $(0.015)$ & $(0.021)$ & $(0.014)$ & $(0.016)$ & $(0.023)$ \\
\hline \multirow{2}{*}{$\begin{array}{l}\text { Financial inclusion (for any } \\
2 \text { indicators) }\end{array}$} & $0.066^{* * *}$ & $0.063 * * *$ & $0.089 * * *$ & $0.148 * * *$ & $0.098 * * *$ & $0.172 * * *$ \\
\hline & (0.009) & $(0.011)$ & $(0.017)$ & $(0.010)$ & $(0.011)$ & $(0.017)$ \\
\hline \multirow{2}{*}{$\begin{array}{l}\text { Financial inclusion (all } 3 \\
\text { indicators) }\end{array}$} & $0.121 * * *$ & $0.119 * * *$ & $0.136 * * *$ & $0.306 * * *$ & $0.204 * * *$ & $0.299 * * *$ \\
\hline & $(0.013)$ & $(0.020)$ & $(0.020)$ & $(0.013)$ & $(0.019)$ & (0.019) \\
\hline \multirow[t]{2}{*}{ Constant } & $0.247 * * *$ & $0.319 * * *$ & $0.219 * * *$ & $0.481 * * *$ & $0.461 * * *$ & $0.529 * * *$ \\
\hline & $(0.041)$ & $(0.051)$ & $(0.068)$ & $(0.008)$ & $(0.008)$ & $(0.015)$ \\
\hline $\begin{array}{l}\text { Household controls } \\
\text { included }\end{array}$ & Yes & Yes & Yes & No & No & No \\
\hline Observations & 1,800 & 960 & 840 & 1,861 & 986 & 875 \\
\hline R-squared & 0.481 & 0.288 & 0.433 & 0.242 & 0.137 & 0.230 \\
\hline
\end{tabular}


Notes: Standard errors are given in parentheses. Main results (rural and urban sub-samples combined) are presented in columns (1) and (4), results from the rural specification are in columns (2) and (5), and results from the urban specification are in columns (3) and (6). Panel A presents estimates for the individual indicators of financial inclusion, while panel B reports estimates for combined indicators. In columns (1)-(3), household observable characteristics are included but are excluded in columns (4)-(6). The control variables include age of household head, household size, log of household per capita income, urban residence, gender, marital status of household head, financial decisions within the household, and dummies for education of household head. *Denotes statistical significance at $10 \%$, **denotes significance at the $5 \%$ level and $* * *$ denotes significance at the $1 \%$ level.

The results in table 3 show that the different indicators of financial inclusion positively explain household wellbeing as expected. The most instrumental of them is access to credit (see panel A of table 3). The estimates are generally higher for the urban specification (see columns 2 and 3, and columns 5 and 6 of table 3 for comparison) and decline as we control for household characteristics (see columns 1-3 and 4-6 of table 3 for comparison). Having access to formal credit significantly increased household wellbeing by 0.152 units, and owning a bank account with a formal institution increased household wellbeing by 0.089 units. Even when all other household characteristics are controlled for, access to formal financial services remains an important determinant of household wellbeing. Masiyandima et al. (2017) show that greater financial inclusion promotes access to some basic indicators of wellbeing.

The remaining results in panel B of table 3 distinguish between households with access to all three indicators of financial inclusion and households with fewer than three indicators. The base category is households with no access to any of the three indicators of financial inclusion. The estimates are highly significant and consistent across all estimations. Again, the estimates are generally higher for the urban specification, and decline as we include other household characteristics. Having only one indicator of financial inclusion, increased the wellbeing score by $10 \%$ if a household has only one of the indicators of financial inclusion, and by $31 \%$ if a household has all three indicators (see column 1, panel B of table 3 ). These estimates are $5 \%$ and $12 \%$ respectively, when we include household level controls.

Conceptually, the motivation for financial inclusion lies in the attempt of households to support their livelihood and improve wellbeing. Access to a bank account with a formal institution and to formal credit (or all three indicators of financial inclusion) play a desired role by positively and significantly contributing to household wellbeing. This suggests that further enhancement of access to financial services in Namibia is needed to improve wellbeing and reduce poverty.

\section{Household Socioeconomic Determinants of Wellbeing}

We control for relevant household demographic and socioeconomic variables in order to predict their relationship with household wellbeing (table 4). 
Table 4: Determinants of household wellbeing

\begin{tabular}{|c|c|c|c|}
\hline Variables & (1) & (2) & (3) \\
\hline \multirow[t]{2}{*}{ Household size } & $0.003 *$ & -0.001 & $0.007 * * *$ \\
\hline & $(0.001)$ & $(0.002)$ & $(0.002)$ \\
\hline \multirow{2}{*}{ Age of household head } & -0.006 & -0.006 & -0.000 \\
\hline & $(0.010)$ & $(0.012)$ & $(0.017)$ \\
\hline \multirow[t]{2}{*}{ Household per capita income } & $0.032 * * *$ & $0.024 * * *$ & $0.037^{* * *}$ \\
\hline & $(0.003)$ & $(0.004)$ & $(0.004)$ \\
\hline Reside in urban areas & $\begin{array}{l}0.082 * * * \\
(0.007)\end{array}$ & & \\
\hline \multirow[t]{2}{*}{ Household head is male } & -0.003 & 0.014 & $-0.022 * *$ \\
\hline & $(0.007)$ & $(0.009)$ & $(0.011)$ \\
\hline \multirow[t]{2}{*}{ Household head is married } & $-0.029 * * *$ & $-0.037 * * *$ & -0.019 \\
\hline & $(0.008)$ & $(0.011)$ & $(0.013)$ \\
\hline \multirow[t]{2}{*}{ Household cooperate in financial decisions } & $0.031 * * *$ & $0.026 * * *$ & $0.035^{* * *}$ \\
\hline & $(0.008)$ & $(0.010)$ & $(0.012)$ \\
\hline \multirow[t]{2}{*}{ Primary education } & 0.018 & 0.011 & 0.029 \\
\hline & $(0.012)$ & $(0.014)$ & $(0.023)$ \\
\hline \multirow[t]{2}{*}{ Secondary education } & $0.102 * * *$ & $0.086^{* * * *}$ & $0.134 * * *$ \\
\hline & $(0.012)$ & $(0.014)$ & $(0.021)$ \\
\hline \multirow[t]{2}{*}{ Tertiary education } & $0.179 * * *$ & $0.135 * * *$ & $0.215^{* * *}$ \\
\hline & $(0.017)$ & $(0.028)$ & $(0.026)$ \\
\hline \multirow[t]{2}{*}{ Constant } & $0.245^{* * *}$ & $0.317 * * *$ & $0.219^{* * *}$ \\
\hline & $(0.041)$ & $(0.051)$ & $(0.068)$ \\
\hline Observations & 1,800 & 960 & 840 \\
\hline R-squared & 0.481 & 0.288 & 0.433 \\
\hline
\end{tabular}

Notes: Standard errors are given in parentheses. Main results (rural and urban sub-samples combined) are presented in column (1), results from rural households are in column (2), and results from urban households are in column (3). *Denotes statistical significance at 10\%, $* *$ denotes significance at the $5 \%$ level and $* * *$ denotes significance at the $1 \%$ level.

The results show that household size, income, residential type, marital status, cooperation in financial decisions, and educational attainment are all important determinants of household wellbeing. The effects are generally higher when the urban specification is considered than when the rural specification is considered (see columns 
2 and 3 of table 4 for comparison). Household income consistently and significantly predicts household wellbeing, with higher monthly income associated with a greater wellbeing score. Household size has a positive relationship with wellbeing; however, the effects are only significant in the main and urban specification.

On the effect of geography, the estimated results suggest that individuals in urban areas have, on average, greater wellbeing than those in rural areas. Being an urban resident increases the wellbeing score by 0.082 units. Cooperation in household financial decisions is also a positive and significant contributor to household wellbeing. Holding all other factors constant, if households cooperate in financial decisions, the wellbeing score will increase between 0.031 units for the main and 0.035 units for the urban specification. Surprisingly, being married has a negative and significant effect on wellbeing. A justification of such a relationship requires detailed information on household dynamics. Such information is not readily available in the data set used in this study. Education of the household head has a positive and significant effect on household wellbeing. Having some tertiary education increases the wellbeing index by 0.179 units, whereas upon completing secondary education, wellbeing increased by 0.102 units.

\section{Instrumental Variables Estimates}

Evidence suggests that estimates of the effects of financial inclusion on wellbeing are likely to be biased if endogeneity is ignored (Koomson et al. 2020). Thus, we extend the analysis in this paper to reduce the potential bias resulting from endogeneity. The endogenous regressor, financial inclusion, is binary and the likelihood ratio test for independence of the equations is used. The likelihood ratio test of independence in all models is significant, suggesting that the null hypothesis of no endogeneity is rejected (Cameron and Trivedi 2010). This implies that the standard Ordinary Least Square (OLS) estimates inconsistently explain the effect of financial inclusion on wellbeing, and therefore, there is a need to interpret the instrumental variable estimates. Comparing the magnitude of the effects of the Two-Stage Least Square (2SLS) in table 5 and table 6 to the OLS endogenous estimates in table 3, shows that the standard OLS underestimates (bias downward) the effect of financial inclusion on household wellbeing. The F-statistics for the bank account and savings ownership is greater than 10 , suggesting that distance to a financial institution is a strong instrument for financial inclusion (Staiger and Stock 1994). However, the value is slightly less than 10 for the credit ownership regression. 
Table 5: SLS regression for the effect of financial inclusion on wellbeing by location

\begin{tabular}{|l|l|l|l|l|l|l|l|l|l|}
\hline Variables & $\mathbf{( 1 )}$ & $\mathbf{( 2 )}$ & $\mathbf{( 3 )}$ & $\mathbf{( 4 )}$ & $\mathbf{( 5 )}$ & $\mathbf{( 6 )}$ & $\mathbf{( 7 )}$ & $\mathbf{( 8 )}$ & $\mathbf{( 9 )}$ \\
\hline $\begin{array}{l}\text { Have formal } \\
\text { bank account }\end{array}$ & $0.13^{* * *}$ & & & $0.20^{* * *}$ & & & $0.12^{* * *}$ & & \\
\hline & $(0.04)$ & & & $(0.04)$ & & & $(0.04)$ & & \\
\hline $\begin{array}{l}\text { Have savings } \\
\text { account }\end{array}$ & & $0.13^{* * *}$ & & & $0.22^{* * *}$ & & & $0.12^{* * *}$ & \\
\hline & & $(0.04)$ & & & $(0.03)$ & & & $(0.04)$ & \\
\hline $\begin{array}{l}\text { Have credit } \\
\text { account }\end{array}$ & & & $0.21^{* * *}$ & & & $0.17^{* * *}$ & & & $0.24^{* * *}$ \\
\hline Constant & $0.18^{* * *}$ & $0.31^{* * *}$ & $0.27^{* * *}$ & $0.44^{* * *}$ & $0.54^{* * *}$ & $0.27^{* * *}$ & $0.17^{* *}$ & $0.25^{* * *}$ & $0.029^{* * *}$ \\
\hline & $(0.05)$ & $(0.06)$ & $(0.04)$ & $(0.07)$ & $(0.07)$ & $(0.05)$ & $(0.07)$ & $(0.08)$ & $(0.08)$ \\
\hline $\begin{array}{l}\text { Distance to } \\
\text { the bank }\end{array}$ & $0.23^{* *}$ & $0.35^{* * *}$ & $0.40^{* * *}$ & $0.34^{* * *}$ & $0.31^{* * *}$ & $0.29^{* *}$ & $0.43^{* *}$ & $0.54^{* * * *}$ & $0.54^{* * *}$ \\
\hline & $(0.10)$ & $(0.09)$ & $(0.10)$ & $(0.08)$ & $(0.08)$ & $(0.14)$ & $(0.17)$ & $(0.14)$ & $(0.14)$ \\
\hline Observations & 1,800 & 1,800 & 1,800 & 960 & 960 & 960 & 840 & 840 & 840 \\
\hline
\end{tabular}

Notes: Standard errors are given in parentheses. Results for the entire sample are presented in columns (1) to (3), results from the rural specification are in columns (4) to (6), and results from the urban specification are in columns (7) to (9). Control variables include age of household head, household size, log of household per capita income, urban residence, gender, marital status of household head, financial decisions within the household, and dummies for education of household head. *Denotes statistical significance at $10 \%$, **denotes significance at the $5 \%$ level and $* * *$ denotes significance at the $1 \%$ level.

Overall, an increase in the level of financial inclusion improves household wellbeing. The results are consistent across the different methodological approaches and measures of financial inclusion. The results also support evidence from previous studies that financial inclusion reduces household poverty and vulnerability (Imai et al. 2010; Koomson et al. 2020; Mohammed et al. 2017; Swamy 2014). Distance to the nearest financial institution has shown to be key in the association between financial inclusion and wellbeing. This can be seen through the observed difference in the estimates of the standard OLS and the 2SLS. For example, having a bank account increases the wellbeing score by $5 \%$ when the OLS method is used, and by $13 \%$ when the 2SLS is used. Similar results are obtained for savings and credit account ownership. Koomson et al. (2020) found that the difference between the IV probit and the standard probit for financial inclusion and poverty reduction, was about $26 \%$.

\section{Locational and Gender Dimension to the Effect of Financial Inclusion on Wellbeing}

The location dimension produces quite interesting findings (column 4 to 9 of table 5). The effect on wellbeing through having a formal bank and savings account is generally higher among rural households, compared to urban households. Having a formal bank account increases the wellbeing score by $20 \%$ for rural households, and by $12 \%$ for urban households, whereas having a savings account increases the wellbeing score by $22 \%$ for rural households, and by $12 \%$ for urban households. On the other hand, having access to formal credit improves wellbeing more in urban areas $(24 \%)$ than in rural areas 
$(17 \%)$. This supports previous findings which demonstrate that financial inclusion reduces the current poverty of rural households by $38 \%$ compared to $22 \%$ for urban households, and future risk of poverty by $39 \%$ and $22 \%$ respectively (Koomson et al. 2020). Given that poverty is largely a rural phenomenon, an improvement in the level of financial inclusion can be regarded as an instrument to better the livelihoods of rural households.

Table 6: 2 SLS regression for the effect of financial inclusion on wellbeing by gender

\begin{tabular}{|l|l|l|l|l|l|l|}
\hline Variables & $\mathbf{( 1 )}$ & $\mathbf{( 2 )}$ & $\mathbf{( 3 )}$ & $\mathbf{( 4 )}$ & $\mathbf{( 5 )}$ & $\mathbf{( 6 )}$ \\
\hline Have formal bank account & $0.013^{* * *}$ & & & $0.083^{*}$ & & \\
\hline & $(0.003)$ & & & $(0.045)$ & & \\
\hline Have formal savings account & & 0.095 & & & $0.142^{* * *}$ & \\
\hline & & $(0.077)$ & & & $(0.044)$ & \\
\hline Have formal credit account & & & $0.164^{* * *}$ & & & $0.245^{* * *}$ \\
\hline & & & $(0.037)$ & & & $(0.027)$ \\
\hline Distance to the bank & $0.091^{* * *}$ & $0.287^{* *}$ & $0.221^{*}$ & $0.459^{* * *}$ & $0.425^{* * *}$ & $0.636^{* * *}$ \\
\hline Constant & $(0.020)$ & $(0.135)$ & $(0.131)$ & $(0.141)$ & $(0.122)$ & $(0.142)$ \\
\hline & 0.099 & $0.219^{*}$ & $0.176^{* * *}$ & $0.259^{* * *}$ & $0.361^{* * *}$ & $0.368^{* * *}$ \\
\hline Observations & $(0.067)$ & $(0.120)$ & $(0.060)$ & $(0.066)$ & $(0.077)$ & $(0.067)$ \\
\hline & 1,024 & 1,024 & 1,024 & 776 & 776 & 776 \\
\hline
\end{tabular}

Notes: Standard errors are given in parentheses. Results for the female sample are presented in columns (1) and (3), and results from the male specification are in columns (4) and (6). Control variables include age of household head, household size, log of household per capita income, urban residence, gender, marital status of household head, financial decisions within the household, and dummies for education of household head. *Denotes statistical significance at $10 \%, * *$ denotes significance at the $5 \%$ level and $* * *$ denotes significance at the $1 \%$ level.

Gender-wise, the effect of financial inclusion on wellbeing is higher among maleheaded households, compared to female-headed households. For instance, having a formal bank account improves the wellbeing of male-headed households by about $1 \%$, while it does so for female-headed households by about $8 \%$. Having a savings account has no significant effect on the wellbeing of female-headed households, but significantly enhances the wellbeing of male-headed households by $14 \%$. Having access to formal credit improves the wellbeing of female-headed households by about $16 \%$, while it does so for male-headed households by about $25 \%$. Thus, in comparative terms, financial inclusion does more in improving wellbeing for male-headed households than it does for their female counterparts. Our findings support those of Swamy (2014) and Koomson et al. (2020), who established that financially included female-headed households experience greater poverty reduction than their male counterparts.

\section{Conclusion and Recommendations}

In this paper, we empirically analysed the relationship between financial inclusion and household wellbeing by utilising household level data as opposed to using macro time series data. This allowed us to extend the analysis of financial inclusion, poverty and 
income inequality. Given that the extent to which the effect of financial inclusion for one country can be generalised to other countries has not been established, country specific studies are required for better policy options. In addition, the magnitudes of the estimates were expected to vary significantly between rural and urban areas and across the different measures of financial inclusion. Generally, the results indicate that estimates of financial inclusion are quite robust for a series of alternative estimations and across different dimensions of financial inclusion.

Financial inclusion estimates are positive and significant, but the magnitudes are found to vary between rural and urban households and with the inclusion of household socioeconomic characteristics (see table 3). The estimates are generally larger when urban households are considered than when rural households are used, and lower when we include household characteristics. However, our findings qualify the general understanding of financial inclusion and household wellbeing by demonstrating that a household can enhance wellbeing when it is financially included.

The study has strong evidence suggesting that household observable characteristics are also crucial in explaining household wellbeing. For instance, the results suggest that household size, income, residential type, marital status, cooperation with financial decisions, and educational attainment, are all important determinants of household wellbeing. The effects are generally higher when the urban specification, rather than the rural specification, is considered (see column 2 and 3 of table 4 for comparison). However, we acknowledge the weakness of using only the indicators of objective wellbeing and recommend that with the availability of data, further studies should consider incorporating aspects of subjective wellbeing. In order to enhance household wellbeing and reduce poverty, especially among the vulnerable population (rural and female-headed households), national and international agencies are required to commit to improving access to financial services. Thus, governments should improve their financial inclusion regulations and institutional frameworks and promote policies that encourage the growth and expansion of both public and private financial services.

\section{Conflict of Interest Statement}

The authors declare that they have no competing interests.

\section{Funding}

The authors received no funding for the research.

\section{References}

Abosedra, S., M. Shahbaz, and K. Nawaz. 2016. "Modelling Causality between Financial Deepening and Poverty Reduction in Egypt." Social Indicators Research 126 (3): 955969. https://doi.org/10.1007/s11205-015-0929-2. 
Akudugu, M. A. 2013. "The Determinants of Financial Inclusion in Western Africa: Insights from Ghana." Research Journal of Finance and Accounting 4 (8): 1-9.

Allen, F., E. Carletti, R. Cull, J. Qian, L. Senbet, and P. Valenzuela. 2013a. Resolving the African Financial Development Gap: Cross-country Comparisons and a Within-country Study of Kenya. The World Bank. https://doi.org/10.1596/1813-9450-6592.

Allen, F., E. Carletti, R. Cull, J. Qian, L. Senbet, and P. Valenzuela. 2013b. Improving Access to Banking: Evidence from Kenya. The World Bank. https://doi.org/10.1596/1813-94506593.

Beck, T., A. Demirgüç-Kunt, and R. Levine. 2007. "Finance, Inequality and the Poor." Journal of Economic Growth 12 (1): 27-49. https://doi.org/10.1007/s10887-007-9010-6.

Brown, M., B. Guin, and K. Kirschenmann. 2015. "Microfinance Banks and Financial Inclusion.” Review of Finance 20 (3): 907-946. https://doi.org/10.1093/rof/rfv026.

Cameron, A. C., and P. K. Trivedi. 2010. Microeconometrics Using Stata, revised edition. College Station, TX: Stata Press.

Chibba, M. 2009. "Financial Inclusion, Poverty Reduction and the Millennium Development Goals." The European Journal of Development Research 21 (2): 213-230. https://doi.org/10.1057/ejdr.2008.17.

Coulibaly, B. S. 2019. "Foresight Africa: Top Priorities for the Continent in 2019.” Africa Growth Initiative, Brookings Institute. https://www.brookings.edu/wpcontent/uploads/2019/01/BLS18234_BRO_book_007_WE B.pdf.

Demirgüç-Kunt, A., L. Klapper, D. Singer, S. Ansar, and J. Hess. 2018. The Global Findex Database 2017: Measuring Financial Inclusion and the Fintech Revolution. The World Bank. https://doi.org/10.1596/978-1-4648-1259-0.

Dolan, P., T. Peasgood, and M. White. 2008. "Do we really know what makes us happy? A Review of the Economic Literature on the Factors Associated with Subjective Wellbeing." Journal of Economic Psychology 29 (1): 94-122. https://doi.org/10.1016/j.joep.2007.09.001.

Duvendack, M., and P. Mader. 2020. "Impact of Financial Inclusion in Low and Middleincome Countries: A Systematic Review of Reviews." Journal of Economic Surveys 34 (3): 594-629. https://doi.org/10.1111/joes.12367.

Haq, W., N. A. Ismail, and N. M. Satar. 2018. "Investigation of Household Debt through Multilevel Multivariate Analysis: Case of a Developing Country." Journal of Reviews on Global Economics 7: 297-316. https://doi.org/10.6000/1929-7092.2018.07.26. 
Honohan, P. 2008. "Cross-country Variation in Household Access to Financial Services.” Journal of Banking and Finance 32 (11): 2493-2500.

https://doi.org/10.1016/j.jbankfin.2008.05.004.

Imai, K. S., T. Arun, and S. K. Annim. 2010. "Microfinance and Household Poverty Reduction: New Evidence from India.” World Development 38 (12): 1760-1774. https://doi.org/10.1016/j.worlddev.2010.04.006.

Jalilian, H., and C. Kirkpatrick. 2002. Financial Development and Poverty Reduction in Developing Countries." International Journal of Finance and Economics 7 (2): 97-108.

Kahneman, D., and A. B. Krueger. 2006. "Developments in the Measurement of Subjective Wellbeing." Journal of Economic perspectives 20 (1): 3-24. https://doi.org/10.1257/089533006776526030.

Khan, M. I., and R. S. Bhandari. 2018. "Financial Inclusion and Economic Wellbeing of Rural Households." International Journal of Creative Research Thoughts 6 (2).

Koomson I., and M. Ibrahim. 2018. "Financial Inclusion and Growth of Non-farm Enterprises in Ghana.: In Financing Sustainable Development in Africa, edited by U. Efobi and S. Asongu. Palgrave Macmillan. Cham. https://doi.org/10.1007/978-3-319-78843-2_14.

Koomson, I., R. A. Villano, and D. Hadley. 2020. "Effect of Financial Inclusion on Poverty and Vulnerability to Poverty: Evidence using a Multidimensional Measure of Financial Inclusion." Social Indicators Research, 1-27. https://doi.org/10.2139/ssrn.3518908.

Kumar, C., and S. Mishra. 2011. "Banking Outreach and Household Level Access: Analyzing Financial Inclusion in India." 13th Annual Conference on Money and Finance in the Indian Economy, 25-26.

Kumar, N. 2013. "Financial Inclusion and its Determinants: Evidence from India." Journal of Financial Economic Policy 5 (1): 4-19. https://doi.org/10.1108/17576381311317754.

Masiyandima, N., K. Mlambo, and S. Nyarota. 2017. "Financial Inclusion and Quality of Livelihood in Zimbabwe." 14th African Finance Journal Conference-Africagrowth Institute.

Mohammed, J. I., L. Mensah, and A. Gyeke-Dako. 2017. "Financial Inclusion and Poverty Reduction in Sub-Saharan Africa." African Finance Journal 19 (1): 1-22.

Namibia Statistics Agency. 2017. "Namibia Financial Inclusion Survey.” NSA, Windhoek, Namibia.

Park, C. Y., and R. Mercado. 2018. "Financial Inclusion, Poverty, and Income Inequality in Developing Asia." The Singapore Economic Review 63 (1):185-206. https://doi.org/10.1142/S0217590818410059. 
Rajan, R., and L. Zingales. 1998. "Financial Development and Growth.” American Economic Review 88 (3): 559-586.

Sarma, M., and J. Pais. 2011. "Financial Inclusion and Development." Journal of International Development 23 (5): 613-628. https://doi.org/10.1002/jid.1698.

Staiger, D., and J. H. Stock. 1994. "Instrumental Variables Regression with Weak Instruments." National Bureau of Economic Research Technical Working Paper No. 151. https://doi.org/10.3386/t0151.

Swamy, V. 2014. "Financial Inclusion, Gender Dimension, and Economic Impact on Poor Households." World Development 56: 1-15. https://doi.org/10.1016/j.worlddev.2013.10.019.

Tita, A. F., and M. J. Aziakpono. 2017. "Exploring the Relationship between Financial Inclusion and Assets Accumulation in South Africa." International Journal of Social Economics.

UNDP. 2014. “Human Development Report 2014” (Technical Note). United Nations Development Program, New York.

World Bank. 2001. "World Development Report 2000-2001: Attacking Poverty.” Accessed July 21, 2017. https://openknowledge.world bank.org/handle/10986/11856. World Bank Group. New York: Oxford University Press.

World Bank Group. 2021. "Namibia Overview." https://www.worldbank.org/en/country/namibia/overview.

Yang, L. 2018. "Measuring Wellbeing: A Multidimensional Index Integrating Subjective Wellbeing and Preferences." Journal of Human Development and Capabilities 19 (4): 456-476. https://doi.org/10.1080/19452829.2018.1474859.

Zins, A., and L. Weill. 2016. "The Determinants of Financial Inclusion in Africa." Review of Development Finance 6 (1): 46-57. https://doi.org/10.1016/j.rdf.2016.05.001. 